\title{
Experiential Learning Programs for the Future of Engineering Education
}

\author{
Amy J. Conger, Brian Gilchrist, \\ James Paul Holloway, Aileen Huang-Saad, \\ Volker Sick, Thomas H. Zurbuchen \\ College of Engineering \\ University of Michigan \\ Ann Arbor, MI
}

\begin{abstract}
The need for $21^{\text {st }}$ century engineers to be educated as creative innovators is discussed. Three complementary experiential learning programs that help engineering students learn to stretch beyond their comfort zones are described: a multidisciplinary design program; an entrepreneurship program; and an international engineering program. These three interdisciplinary programs each address common educational needs: to create flexible, creative, self-actualized change agents. The approaches we are taking to implement and institutionalize these in a large, comprehensive, research oriented university are described.
\end{abstract}

Keywords-component; experiental, multidisciplinary; design; design build test; entreprenurial; international

\section{INTRODUCTION}

A recent report from the Carnegie Foundation for the Advancement of Teaching [1] examined six US engineering schools and noted a continuing and widespread emphasis on textbook-centric theory over hands-on practice, an approach that discourages many students and largely leaves them unprepared for real-world problems.

Our experience suggests that engineering students arrive at school typically excited about doing engineering and design and hopeful about their potential future impact. Yet they often have very little basis to understand what that really means, or to comprehend the connection between their classroom knowledge and professional practice, and have little opportunity to experience the profession into which they are seeking entry. Important pressures also exist for our industrial "customers" who must be able to respond to the need for increasingly complex problem identification and solutions, requiring more sophisticated skills in professional practice from our graduates. In addition, there are broad expectations that universities will have economic impact and produce graduates who themselves have economic impact. If we are not able to better prepare our students, there will be a delay between the time of graduation and the time when our graduates can become effective innovators, and the benefit that our profession can bring to society will be lessened.

Most engineering programs, including those at the University of Michigan's College of Engineering (CoE), developed an engineering science focus that provides students with a solid foundation in fundamental science, mathematics, and engineering analysis for a post-World War II manufacturing economy $[2,3]$. However, the economic drivers for the $21^{\text {st }}$ century are different from those that dominated when our current curricula were created. The $21^{\text {st }}$ century market seeks innovation and demands engineers who can conceive and create new classes of products and services. In many cases a company's success will not be due to routine engineering, but rather due to the design, the emotional reaction of the customer to the product, and to its social appropriateness [4]. Our students therefore need to understand the bigger picture of engineering: a systems perspective, an entrepreneurial perspective, and a global perspective. Some have argued [1] that this should be a central educational element developed in parallel with problem solving skills.

Michigan's CoE has a strong emphasis as a research institution, with a graduate to undergraduate student ratio of approximately $1: 2$. The $\mathrm{CoE}$ is expanding its undergraduate programs to demonstrate new approaches to engineering education with the goal of preparing the next generation of engineering innovators and leaders to impact our changing world. Michigan's programs have two distinct challenges:

1. scalability: the CoE currently enrolls nearly 5500 undergraduate students;

2. breadth of programs: the CoE currently offers 15 academic bachelor degrees.

So, to continue to provide the excellent engineering education that our students require, we must foster the learning of innovation and develop our students' ability to define problems, envision answers, implement solutions, and bring those solutions to the marketplace, and we must do so in a research-focused engineering school with a large undergraduate population.

The implementation strategy we are pursuing has twosteps, with the first step to develop three co-curricular programs as complements to the bachelor degree programs, allowing students from across degree programs and even outside of the $\mathrm{CoE}$ to collaborate as appropriate. In these programs, instructional and practicum needs are flexibly 
addressed and performance is tracked. A second step will be the infusion of lessons learned into the broader curricula of our bachelor degree programs so that more students are routinely affected by these new educational approaches.

This paper describes the implementation phase of the three new initiatives: Multidisciplinary Design, Entrepreneurship, and International Programs.

1. The Multidisciplinary Design Program puts students from a range of disciplines to work on significant, open-ended, real world multidisciplinary design projects that include design, build and test (DBT) elements.

2. The Entrepreneurship Program helps all COE students develop an entrepreneurial mindset and helps them realize the potential of the products they create and of themselves as change agents.

3. The International Program helps students integrate foreign language proficiency, coursework on non-U.S. countries and intercultural communication skills, and practical overseas experience through study, work or volunteering abroad.

While our traditional engineering science programs teach our students mostly about engineering theory, these new experiential programs help our students learn how to be creative engineers. Identifying opportunities and understanding social contexts go hand-in-hand, so these co-curricular programs also seek to integrate our students' technical knowledge and problem solving skills with an understanding of engineering practice in different social and global contexts.

As these programs show success by increasing engineering student wisdom as creative and innovative change agents, and as we put incentives in place to embed the most appropriate aspects of these programs into the regular degree programs, we expect to achieve large-scale institutionalization in a large research university.

\section{MULTIDISCIPLINARY DESIGN PROGRAM}

In summarizing the Carnegie Foundation report [1], its authors noted [5] "The central lesson that emerged from the study is the imperative of teaching for professional practice with practice understood as the complex, creative, responsible, contextually grounded activities that define the work of engineers at its best; and professional understood to describe those who can be entrusted with responsible judgment in the application of their expertise for the good of those they serve." To be even more specific, Duderstadt [3] notes "... it is long past time that we ripped engineering education out of the lecture hall and place it instead in the discovery environment of the laboratory, the design studio, or the experiential environment of practice."

To focus on the creative engineering design process in a multidisciplinary world, Michigan's College of Engineering created the Multidisciplinary Design (MD) Program in 2009. It has as its goals

- To support the needs of students to prepare for a multidisciplinary world that
- Addresses professional practice ("Learning to be") through an experiential process of creative engineering in a multidisciplinary environment;

- Promotes a broad spectrum of high quality experiential, multidisciplinary DBT opportunities that is sustainable and that engages other schools/colleges at Michigan as well as outside partners from industry, government, and other appropriate organizations;

- Motivates and deepens the understanding of classroom acquired knowledge along with laying the foundation for the skills to be life-long learners.

- To curricularize these activities for the benefit of our students and to work with departments and schools to integrate open-ended, multidisciplinary creative engineering experiences into their curricula.

The MD Program's vision is to work in layers of opportunity and engagement for students, departments/colleges/schools, and external partners. This starts with early experiences for freshmen and sophomores, includes integrating real-world experiences as part of traditional capstone major design experience courses, and promoting multi-semester experiences that span a complete design-buildtest (DBT) cycle (also including requirements definition and operational aspects of any creative engineering endeavor). The latter is a major part of a Minor in Multidisciplinary Design [7] now available at Michigan.

In developing the new Multidisciplinary Design Program, we have been able to draw upon numerous examples of student-led DBT projects already in place at Michigan that have successfully attracted and integrated multidisciplinary groups of students to work on real-world projects. These span activities focused on societal needs, a wide range of competitions, and even research and development. Specific examples include student teams developing and implementing cleaner cooking fuel technology for villages in Nicaragua, genetically engineering new bio-systems, designing and racing sophisticated solar cars (leading to 5 national championships since 1990), and building and flying nano-satellites in space or in a NASA microgravity aircraft. Many universities will have similar examples. These projects inherently include many of the features that we believe are important in the education for professional practice as described above.

To understand the MD Program, it is best to first understand the elements of its Multidisciplinary Design Minor that is organized in to four required elements. These are summarized in Figure 1.

1. Introductory DBT requirement: The introductory Design, Build, Test requirement is meant to give students their first immersion experience in a small engineering team project. This is where students first learn what it is like to go through the whole DBT process but on a smaller scale. This is most usefully done in the freshman or sophomore year.

2. A preparatory course requirement: Students are required to take a "cornerstone" course that serves to prepare them in depth for the multi-term major design, build, test, requirement. This requirement is to be taken outside of 
the student's major department and required degree course work.

3. Major DBT requirement: The major design, build, test requirement is a multi-term, multidisciplinary project that gives students the opportunity to 1) identify the problem through qualitative and/ or quantitative requirements, 2) generate creative solution concepts, 3) analyze the quality of proposed concepts, 4) select and optimize the final concept, 5) evaluate the final concept through the building and testing of prototypes or virtual models, and 6) iterate and/or detail recommendations for improvement of the final concept based on the lessons learned from the previous steps.

4. Mentorship and/or Leadership requirement: The leadership/mentorship requirement of this program is to help encourage and to pass on knowledge to less experienced design project students (the same project or other student design projects including for example high school or middle school projects) as well as to reinforce learned abilities in the senior team members. In addition, it provides possible human resources to allow the DBT teams to grow and sustain themselves over the years without faculty needing to provide all of the mentoring of team members.

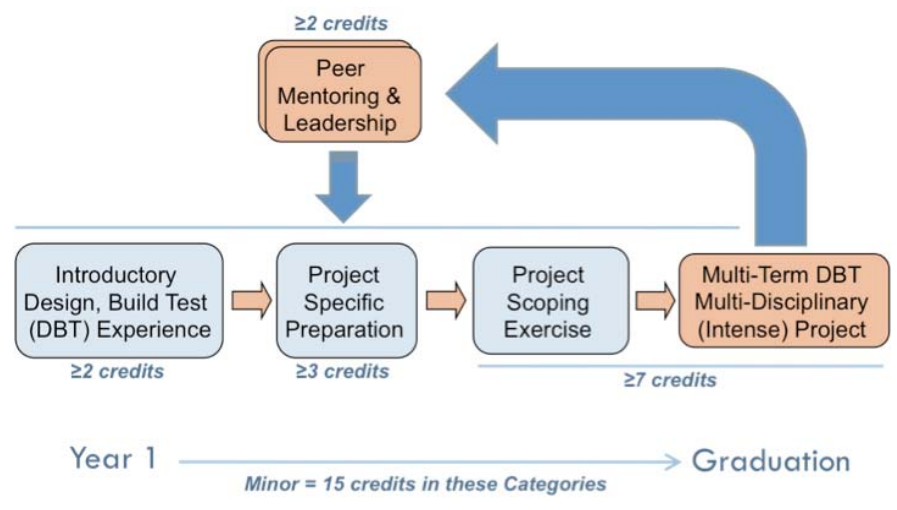

Figure 1: MD Minor template. A multi-year experience.

An important consideration in the development of the MD Minor was capturing the enthusiasm of faculty and students to tackle new and exciting design challenges. Thus, we are encouraging specializations within the minor to attract students and faculty around topics of current interest. Specializations currently being developed include topics such as Space Systems, Global Health, Sustainable Energy, Service Learning, and Campanology (with the Schools of Music and Art and Design). A student completing the requirements for a specialization within the MD Minor will have this specialization reflected on his or her transcript (e.g., "Minor in Multidisciplinary Design - Global Health"). While these specializations can be tailored to the passions of specific faculty groups and students, an umbrella Minor in Multidisciplinary Design also exists so that being a part of a specialization is not required to receive the MD Minor.

While in some ways the MD Minor can be thought of as the heart of the Multidisciplinary Design Program, we do not expect every undergraduate will or even should earn this minor.
However, a goal of working with departments of the College of Engineering to integrate multidisciplinary and DBT experiences broadly in the undergraduate curriculum drives our overall efforts. For example, the College of Engineering, working with departments, has actively promoted the creation of sections of our required introductory freshman course (ENG 100, serving some 1,300 students each academic year) that have hands-on DBT activities (See for example [7]). Students who take these sections, automatically meet the first requirement of the MD Minor.

We also are working to collaborate with both the Entrepreneurial and International Programs in Engineering to promote common, synergistic student experiences. For example, a student who is earning the International Minor by traveling and working abroad at a company certainly is obtaining multidisciplinary and possibly multidisciplinary design experience. Similarly, an entrepreneurial student initiative taken to an implementation phase likely provides multidisciplinary design experience and possibly DBT experience as well. We feel that with a large student population having a diversity of interests it is critical to encourage a wide range of opportunities.

\section{ENTREPRENEURSHP PROGRAM}

The Center for Entrepreneurship (CFE) and the first of its associated academic programs were established in January 2008. All of the CFE's activities are focused on the development and empowerment of students with a mindset focused on entrepreneurial activities in small companies, big companies, and also in the public sector. "Entrepreneurship is a particular type of mindset, a unique way of looking at the world....At the heart of entrepreneurship lies the desire to achieve, the passion to create, the yearning for freedom, the drive for independence, and the embodiment of entrepreneurial visions and dreams through tireless hard work, calculated risktaking, continuous innovation, and undying perseverance.[8]"

The entrepreneurship program has multiple engagement levels (Figure 2).

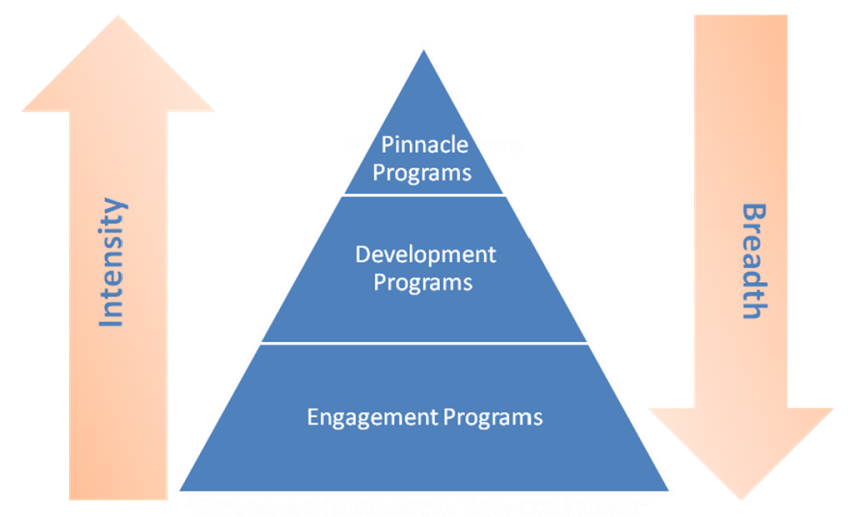

Figure 1: The U-M Multi-level Entrepreneurship Strategy.

The foundation of the entrepreneurship strategy is formed by engagement programs deployed individually or as parts of classes focused on developing the entrepreneurial mindset in all College of Engineering students. The next higher tier is 
formed by dedicated classes and programs, often in conjunction with hands-on activities that focus on entrepreneurship as a laboratory. Intense and focused programs that help students implement their entrepreneurial endeavors form the top of our educational pyramid.

Within each tier, there are three main thrusts, Academic Programs, Community Engagement and Venture Acceleration (Table 1). The Academic Programs focused on Entrepreneurship are therefore closely connected with Community Engagement and Venture Acceleration programs with specific focus and depth. These thrusts were developed to meet the needs of successful entrepreneurship being associated with an entrepreneurial community, from students interested exploring the entrepreneurship, to students ready to launch a venture today, to community partners (Table 1). The different tiers and thrusts belong together and students move through these tiers depending on their depth and interests. Together, these programs provide a broad spectrum of opportunities in entrepreneurship for all.

\begin{tabular}{|c|c|c|}
\hline Academic & $\begin{array}{l}\text { Community } \\
\text { Engagement }\end{array}$ & $\begin{array}{c}\text { Venture } \\
\text { Acceleration }\end{array}$ \\
\hline \multicolumn{3}{|c|}{ Pinnacle Programs } \\
\hline $\begin{array}{l}\text { Graduate Program } \\
\text { in High-Tech } \\
\text { Entrepreneurship }\end{array}$ & $\begin{array}{c}\text { Bay Area } \\
\text { Trip/TechFest }\end{array}$ & Tech Arb \\
\hline \multicolumn{3}{|c|}{ Development Programs } \\
\hline $\begin{array}{l}\text { Program in } \\
\text { Entrepreneurship }\end{array}$ & $\begin{array}{l}\text { Small Company } \\
\text { Innovation } \\
\text { Program and } \\
\text { Internships }\end{array}$ & Mentorships \\
\hline \multicolumn{3}{|c|}{ Engagement Programs } \\
\hline $\begin{array}{c}\text { Distinguished } \\
\text { Innovators Speaker } \\
\text { Series }\end{array}$ & $\begin{array}{c}\text { Sponsored } \\
\text { Community Meet- } \\
\text { up Events }\end{array}$ & 1000 Pitches \\
\hline
\end{tabular}

Table 1. The UM CFE Strategy with respect to Tiers and Thrusts

At the Engagement level, the Entrepreneurship Programs are contained of scalable, high-impact programs that expose broad audiences to the basics of entrepreneurship. Each semester, any U-M student can enroll in ENGR407: The Distinguished Innovators Speaker Series (Academic Thrust). This campus wide course is available for course credit and open to the community. Students are invited to participate in sponsored community meet-up events with our community partners which provide them contacts with experienced entrepreneurs (Engagement Thrust). Through these activities, students and community partners are encouraged to share ideas, opportunities, and experiences. The Entrepreneurship Program also contains the largest university-based idea competition, set up in collaboration with the University entrepreneurship student group, MPowered, the CFE co-sponsors the 1000
Pitches competition (Venture Acceleration). This unique collegiate pitch competition encourages all members of the UM community to express their ideas through an on-line video submission process. Pitches are judged across several categories including, health, environmental, social entrepreneurship, global business, green campus, local business, Michigan matters, high-tech and iPhone applications. In its first year of implementation (2008), over 1000 pitches were submitted. These numbers were surpassed in year two by more than a factor of two, with well over 2000 submissions.

As opposed to engagement programs, which are designed to encounter the maximum number of students, second tier programs are moderately intense and provide practical and multidisciplinary experiences in entrepreneurial education. Most of the second-tier classes are based on the motto "Entrepreneurship is not a class - it's a Lab": Classes are primarily focused on entrepreneurial activities and not just entrepreneurial knowledge. Students interested in pursuing an entrepreneurship academic program can enroll in the "Program in Entrepreneurship". The Program in Entrepreneurship is an academic program that provides University of Michigan students an opportunity to explore entrepreneurship without taking away from their technical education. The program allows students to take four unique entrepreneurial courses for a total of at least 9 credit hours. Upon completion of the program, engineering students have this experience recognized on their transcript. The curricular elements of the program are the Distinguished Innovators Seminar, a core course in entrepreneurship, an elective course in entrepreneurship, and the capstone entrepreneurial practicum. Core and elective courses are offered throughout the university in various departments to address specific technical areas, including biomedical [9] and aerospace [10] engineering. We also encourage our students to supplement classroom learning with more in-depth community involvement for Development Programs including co-funded summer internships with startup ventures and the Small Company Innovation Program. The Small Company Innovation Program is a University-funded cost sharing program through which small companies can perform joint research with UM faculty, through direct engagement of a PhD student. We have also established a wide network of mentors actively engaged and passionate about mentoring UM students interested in launching their own student-driven ventures. Mentors are drawn from local community partners and the national UM alumni base.

The top tier programs (Pinnacle) are intense and focused programs that provide a high level of knowledge transfer and business formation acceleration. These programs are focused on students who are creating entrepreneurship as a key emphasis of their academic experience, often preparing a career as an active entrepreneur. After Fall 2011, graduate students will have the opportunity to enroll in a graduate level program designed to arm students with the critical multidisciplinary knowledge needed to create new technology ventures and to create value of novel technologies within the context of entrepreneurship itself. This program will give students the opportunity to immediately put their new found knowledge to use through a "living laboratory," where they identify viable opportunities and work to launch products and companies. 
This real-world application of their academic skills will reinforce their educational experience while generating an environment that cultivates the critical characteristics of an entrepreneur. These characteristics are critical for a student's success, regardless of the student's ultimate career path, be it a start-up venture or a Fortune 500 company.

For the past three years, these academic activities have been supplemented by active efforts to develop connections between entrepreneurial students and their potential partners in the San Francisco Bay area. There, UM students, and faculty can meet with world famous companies, entrepreneurs, venture capitalists and UM alumni for three days of meetings, presentations, networking and sharing of ideas. This experience has been described as a "life changing" experience and also demystifies the Silicon Valley experience. The partner experience to the Bay Area Trip is "Tech Fest," where the CFE brings national entrepreneurship to UM. UM entrepreneurs and venture capitalists are invited to UM for a day of presentations, networking and sharing of ideas, Finally, for students actively pursuing their entrepreneurial dreams while attending UM, a student business incubator was established in 2009, Tech Arb [11]. Students can use Tech Arb co-locate with other student companies and work on launching their own ventures.

Today's students will have to compete in a global economy where the rate of technology development outpaces their education and they are constantly pushed beyond the limitations of their education. Engineers no longer can rely on a one-job career in a traditional engineering discipline, such as mechanical, electrical, or chemical engineering. Career choices have transitioned to include multidisciplinary pursuits driven by organizations of all sizes. That's why all activities in table 1 are generally open to all UM students, irrespective of their major or home-college. While our students may or may not choose to be the business drivers of their organizations, they must in every case be cognizant of the role they play as technology leaders and be prepared to drive the organization forward. It is this awareness and mindset that we work to provide our U-M students.

\section{INTERNATIONAL PROGRAM}

The mission of International Programs in Engineering (IPE) is to significantly increase the number of students who gain international experience during their CoE careers. We define this experience broadly to include study, internships, volunteer work and research outside the United States. The development of these programs aligns with a broader movement in engineering education towards preparing students "to adapt to changes in global forces and trends and to ethically assist the world in creating a balance in the standard of living for developing and developed countries alike [12]."

While CoE study and work abroad opportunities have been in place for several years, many of our US students perceive international experience as uncomfortable, unfamiliar and unrelated to their future profession. These same factors are the most valuable points of our programs, which take students outside their comfort zones, teach them to adapt to new settings and learn what it means to study and practice engineering in different parts of the world. In order to scale up participation, we needed to build a stronger curricular link to international experience and move IPE from extra activities for a select few to relevant educational experience for all engineering undergraduates.

When our work began in 2007, no academic minors existed within the CoE. Engineering undergraduates with global interests could elect minors from our College of Literature, Science and the Arts (e.g. German or Spanish) or pursue the certificate Program in Global Engineering (PGE), an international concentration that was being piloted with a small group of high-achieving students. During the same year, a faculty and staff task force issued recommendations for the future of $\mathrm{CoE}$ international programs. An important part of the task force's work was a college-wide survey of our undergraduates, complemented by focus groups and individual student interviews. The results showed strong student interest in international experience, but suggested that greater structure and space were needed for these activities within the academic plan. Students also desired official recognition for their international work and expressed serious concerns about extending time to degree.

This feedback pointed to the creation of an academic minor that would improve upon the pilot PGE and appeal to a broader range of $\mathrm{CoE}$ undergraduates. We based our implementation strategies on the guiding question: What learning outcomes do we hope students will achieve through international experience? The answers fell into three general categories: knowledge, communication and professional competency. Knowledge means understanding different cultures, countries, social settings and the ways that these contextual factors interact with technology. Communication refers to the linguistic, intercultural and interpersonal skills needed to gather information, articulate ideas and work effectively with people from diverse backgrounds. Professional competencies include the ability to analyze cultural differences, view problems from multiple perspectives and creatively adapt engineering approaches accordingly.

We structured the minor to cut across these three areas and where possible, utilized existing social science and humanities credits that were already required for our BSE programs. Minor requirements include: proficiency in a language other than English (minimum of fourth semester college-level study); coursework on non-US cultures or countries; relevant overseas experience; and a newly designed international engineering course. This new course, offered as an ENGR 490: Special Topics section, examines the role of local culture in engineering problem definition and solution specification. Students look at real-world social challenges and conduct culture-specific needs assessments for the proposed engineering solutions. A diverse group of students enroll in the course each term - from first-year students who have not yet travelled to upper-level students returning from overseas. The mix of students enriches class discussions and provides a forum where returning students can reflect on lessons learned and mentor students who are still planning their own international experiences. 
The same learning outcomes drive the development of new international opportunities and co-curricular programs. $\mathrm{CoE}$ study abroad programs purposefully combine technical coursework with cultural immersion, utilizing host country faculty and maximizing interaction with local students through shared accommodation, joint classes and collaborative projects. Co-curricular programs such as our mandatory pre-departure orientations now include modules on intercultural communication and research assignments about the local culture and engineering trends in the students' host countries. Returning students participate in our Unpacking your International Experience program, a series of workshops that help students identify the lessons and transferable skills they learned overseas and apply them to future engineering courses, graduate programs or careers.

The launch of the minor supported IPE growth by raising visibility about our programs and expanding our pipeline of incoming students who will study, work, volunteer or conduct research abroad during their undergraduate careers (Figure 1). Nearly 150 students are currently enrolled in the minor and 19 have already graduated with this credential.

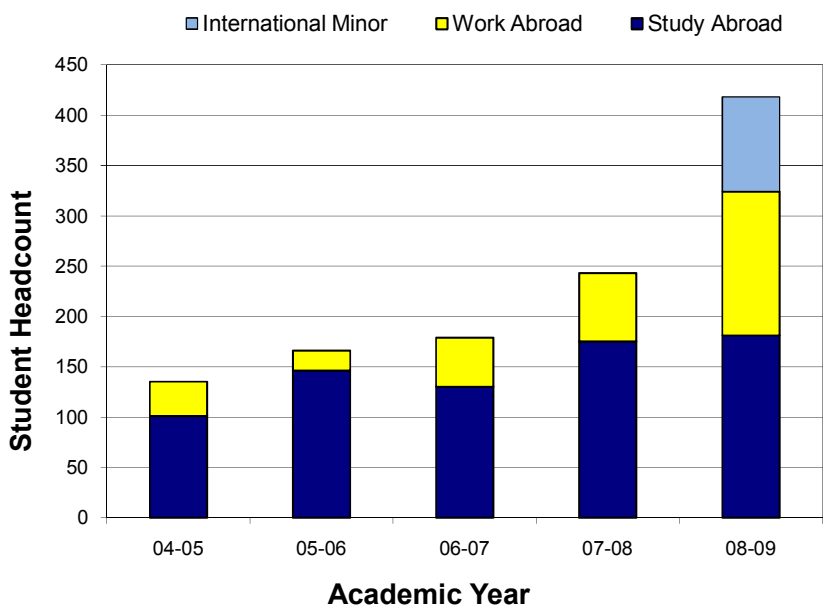

Figure 1: International Programs in Engineering Participation 2004-2009.

In our experience, the minor created a vital curricular link between international learning and our regular engineering programs. Its structure aides students in their academic planning and the formal credential sends a clear message about the value of international experience within the $\mathrm{CoE}$.

\section{OUTLOOK AND CONCLUSIONS}

To create the engineers of the future the $\mathrm{CoE}$ is exploring educational programs that teach our students to develop their creativity, help them to understand the needs and drivers of the wider world, encourage them to innovate, and empower them to make their innovations manifest in the world. But to have sustained impact these new educational approaches must be institutionalized and sustained within the regular degree programs of the College. In 2008 the College charged the Commission on Undergraduate Engineering Education with reviewing our curricula and making recommendations for the future. The Commission recommended [13] that "to prepare our students for the jobs of the $21^{\text {st }}$ century, whether they continue in engineering or pursue other paths after graduation, our undergraduate programs must support our students in developing:

- An ability to recognize and define a problem, and the vision to see a solution

- An ability to identify, understand, and solve ill-defined problems even in the face of uncertainty and imperfect information

- $\quad$ Strong quantitative and qualitative problem solving skills

- A mindset and skills that support continued learning both during and long after their CoE career

- Personal attributes of success including:

○ high personal expectations

○ persistence

○ the ability to work in teams

o the ability to plan a project and carry it out

o the ability to gather resources and overcome barriers to success

○ the ability to manage risk

- An understanding of the human, social, and environmental dimension of engineering practice

- A drive and capability to make a difference by bringing their solutions into production"

The report encouraged the degree programs to develop a structure in which open-ended program and experiential activities - dealing with ambiguity and problems without a single "right" solution-start in each student's first year and continue with increasing sophistication into the sophomore, junior and senior years. At a retreat of $\mathrm{CoE}$ faculty to discuss the report there was clear support for the development of experiential curriculum in various forms. To incentivize this a Curricular Innovation Fund is being piloted in February 2010 to provide faculty with resources to introduce such open-ended problems into their lecture and laboratory classes, and as part of the proposal process faculty must describe a plan to both sustain their curricular innovation after the initial funding is used, and to share it with their colleagues. In this way we hope to continue and institutionalize some of our experiential learning experiments.

The real world offers endless challenges and opportunities for our engineering students both before and after they complete their formal undergraduate education. Many of these challenges are intrinsically multidisciplinary and require work across the boundaries of traditional educational programs. Much of their work will require our graduates to identify and understand the needs of people very different from themselves, and to work in teams that are diverse across the many dimensions of human diversity-multiethnic, multinational, multi-gender, multiracial. As they do this work and come to see the opportunities to make an impact in the world they will need to be confident in the value of their own ideas and have the tools necessary to bring their ideas into practice through both entrepreneurial and intrapreneurial activity. Too often engineering programs fail to mirror this multidisciplinary reality, but instead stovepipe student experiences along 
disciplinary boundaries (often excluding non-engineers entirely) and fail to provide the touchstone of reality that comes from actually implementing a design. Too often our programs fail to empower students with the practice to make their solutions to the worlds problems manifest. The experiential programs we have describe here are designed to test and to curricularize new approaches to helping our students learn these critical $21^{\text {st }}$ century truths, and to do so in a large research intensive, comprehensive university.

\section{ACKNOWLEDGMENTS}

The initiation of the Multidisciplinary Design Program was in part supported by the University of Michigan Provost and College of Engineering as part of a Multidisciplinary Learning and Team Teaching Initiative.

\section{REFERENCES}

[1] Sheppard, Sheri D., Kelly Macatangay, Anne Colby, William M. Sullivan, Educating Engineers: Designing for the Future of the Field. The Carnegie Foundation for the Advancement of Teaching, 2008

[2] Duderstadt, James J., A Roadmap to Michigan's Future: Meeting the Challenge of a Global Knowledge-Driven Economy. The Millennium Project, University of Michigan, Universtity of Michigan, 2005.

[3] Duderstadt, James J., Engineering for a Changing World. Ann Arbor: The Millennium Project, 2008.

[4] Pink, Daniel, A Whole New MInd. Riverhead Books, 2005.
[5] Sheppard, Sheri D., Kelly Macatangay, Anne Colby, William M. Sullivan, Educating Engineers - Book Highlights; The Carnegie Foundation for the Advancement of Teaching; Winter 2008 http://www.carnegiefoundation.org/dynamic/publications/elibrary pdf 7 69.pdf.

[6] Brakora, J., B. Gilchrist, J. Holloway, N. Renno, S. Skerlos, T. Teorey, P. Washabaugh, D. Weinert, Integrating Real-World Experience into a College Curriculum using a Multidisciplinary Design Minor, American Society of Engineering Education Annual Conference, AC 2009-2282, Austin, TX, June 14-17, 2009.

[7] Washabaugh, P.D., Olsen, L.A., Kadish, J.M., "An experiential introduction to aerospace engineering", AIAA Aerospace Sciences Meeting and Exhibit, 2007-296, January 2007.

[8] Ma, H. and J. Tan, Key components and implications of entrepreneurship: A 4-P framework. Journal of Business Venturing, 2006. 21(5): p. 704-725.

[9] Huang-Saad, A.Y., Fostering the Entrepreneiral Mindset in the Engineering Classroom. $39^{\text {th }}$ ASEE/IEEE Frontiers in Education Conference, October 18-21, 2009.

[10] Zurbuchen, T. H. and R. A. Falor, "Low-cost imaging system for novel commercial applications," 2007 IEEE Aerospace Conf. Proc., IEEEAC paper \#1428, 2007

[11] Huang-Saad, et al., Organic Development of a Student Run Accelerator at the University of Michigan. 2010 NCIIA Annual Conference Proceedings.

[12] National Academy of Engineering (2004), The Engineer of 2020: Visions of Engineering in the New Century. Washington, D.C.: National Academies Press.

[13] Michigan Engineering 2020, The Commission on Undergraduate Engineering Education: Curriculum for the $21^{\text {st }}$ Century. 


\title{
Experiential Learning Programs for the \\ Future of Engineering Education
}

\author{
MichiganEngineering
}

Authors:

Amy Conger, Brian Gilchrist*, James Holloway, Aileen Huang-Saad, Volker Sick, Thomas Zurbuchen * Presenter

\section{Calls for Change}

- Educating the Engineer of 2020 (National Academy of Engineering, 2005)

- Educating Engineers for the $21^{\text {st }}$ Century (Royal Academy of Engineering, 2007)

- Moving Forward to Improve Engineering Education (National Science Board, 2007)

- Engineering for a Changing World (Millennium Project, Duderstadt, 2008)

- Educating Engineers: Designing for the Future of the Field (Carnegie Foundation, Sheppard et al, 2008)

- Creating a Culture for Engineering Education Innovation (ASEE, 2009)

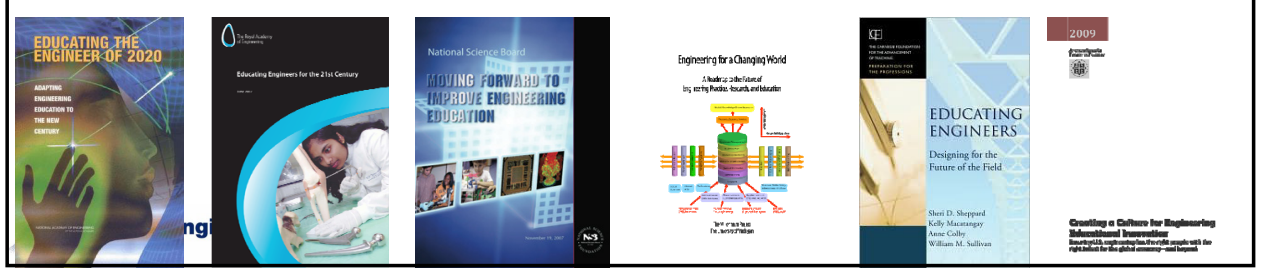




\section{Drivers for Change}

- The $21^{\text {st }}$ Century Market seeks:

- Innovation and new classes of product and service

- Customer satisfaction and quality

- Global impacts of climate change, environmental quality, and sustainability

- US students losing interest in engineering

- Students approach their learning differently

- Engineering services available worldwide

- Engineering analysis is becoming a commodity

- But creativity and design are in demand

MichiganEngineering

\section{How to Respond at UM CoE?}

- Scalability: Currently enroll nearly 5500 undergraduate students

- Breadth of Programs: Currently offer 15 academic bachelor degrees 


\section{The Other Half of Engineering Education}
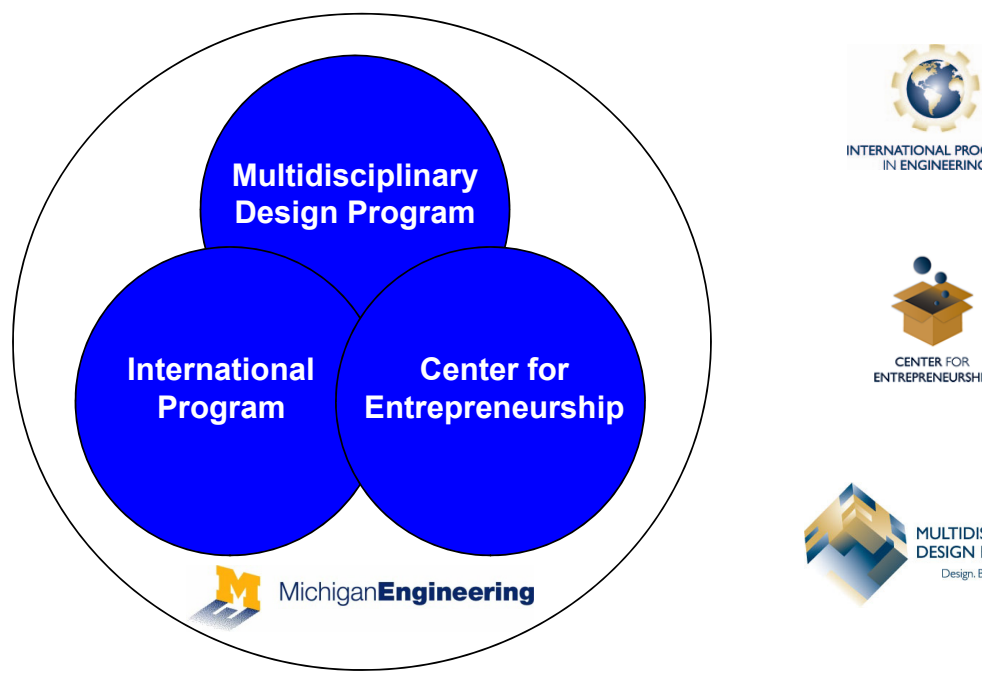

INTERNATIONAL PROGRAMS
IN ENGINERRING

Multidisciplinary

Design Program

ternational

Center for

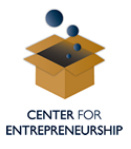

\section{International Programs}

Goal: Significantly increase the number of engineering students who gain international experience during their UM careers (from current rate of $25 \%$ to at least $50 \%$ of each graduating class)

Strategy: Integrate international experience into the engineering curriculum

\section{Learning Outcomes:}

-Knowledge

- Communication

-Professional Competency

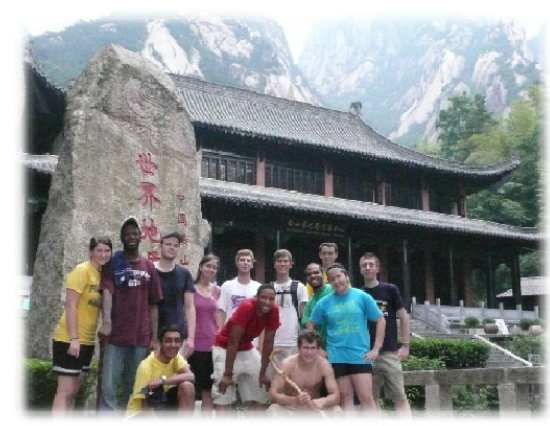




\section{International Minor for Engineers}

\section{Background}

- First minor in the history of the College

- Launched in September, 2008

- 139 CoE students enrolled; 19 already graduated

\section{Requirements}

- 16-20 credits total

- Foreign language prerequisite

- Foreign language proficiency (4th semester collegelevel)

- International courses (non-U.S. cultures/countries)

- International engineering course

- Relevant overseas experience

\section{Our Entrepreneurship Strategy}

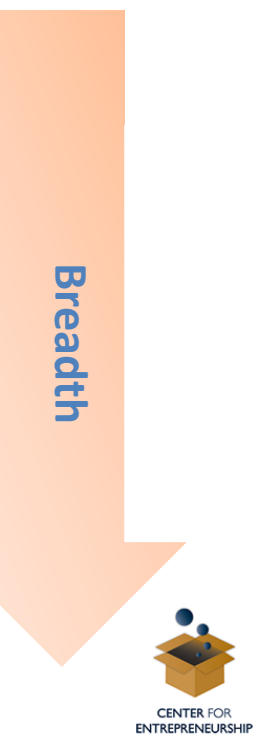



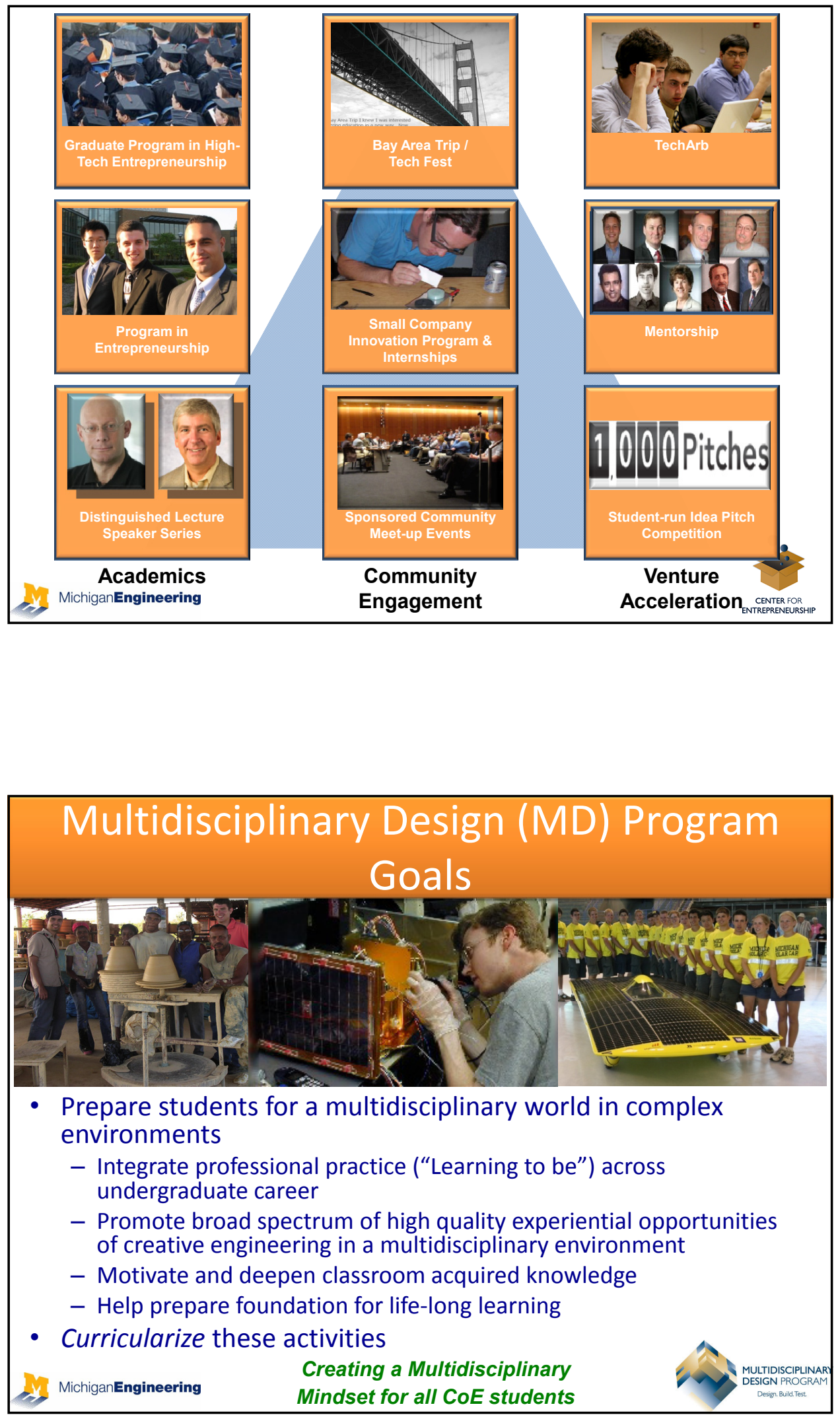


\section{Program Strategy}

- Implement layers of opportunity and engagement for students, departments/colleges/schools, and external partners

- Early experiences for Freshmen/Sophomores

- Enhance traditional capstone design courses with real-world, multidisciplinary projects

- Promote significant multi-semester, design-build-test (DBT) opportunities

\section{Minor in}

Multidisciplinary

Design (15 credits)

Michigan Engingear 1

Year 1

Graduation

\section{Opportunities (Successes)}

- Strong Student Interest

- Strong and Growing external sponsor interest

- College-level initiative

- Allowing more rapid innovation/prototyping

- Minors and Certificates useful tool

- Giving time for departments/faculty to study, understand, and integrate in to curriculum

- Connecting to graduate school 


\section{Challenges}

- Getting faculty/departments on board

- Faculty time constraints

- ABET Constraint to Rapid Innovation

- Flexibility in curriculum for experiential learning

- Coordination across units -

- Different cultures

- Greater diversity of interests

- Managing different academic schedules

- Scaling up opportunities and participation

- "Match Making"

- Funding/Resources

MichiganEngineering

\section{Summary}

- Path finding how to change/improve the way our students are educated in the $21^{\text {st }}$ Century

- Preparing our students to be sophisticated, wiser, adaptive, well-rounded global citizens and professionals

- Utilizing lessons learned from experiential learning in the regular classroom setting

- Supportive university and college leadership are critical innovation and cultural change 